\title{
Improvising information technology projects through the duality of structure
}

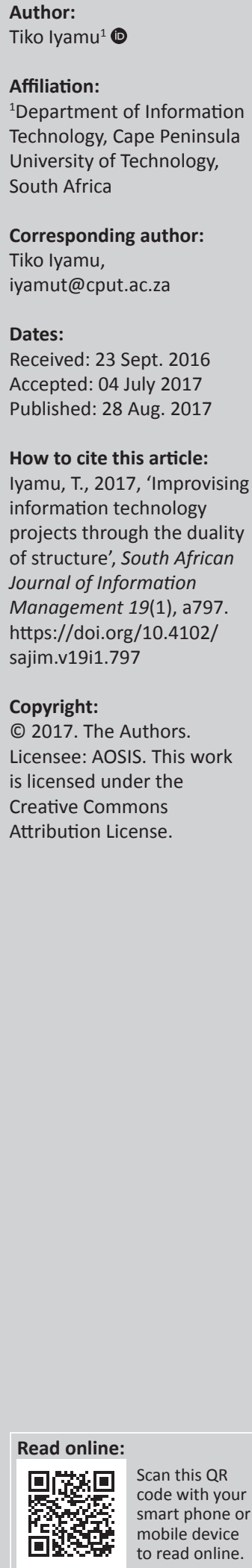

Background: There is always emphasis on information technology (IT) projects because of their significance in organisations. Thus, efforts and resources are reciprocally committed to ensure the successes. Still, failure of IT projects in many organisations remains high and affects competitiveness. As recourse for remedy, different techniques and approaches have been employed. However, little or no progress has been made in increasing the success rate of IT projects in many organisations.

Objectives: The objective of this study was to examine the factors that influence and impact IT projects, improvisation and how improvisation manifests.

Method: The study was carried out using a single case study approach. Qualitative data were collected and duality of structure from the perspective of structuration theory was used as lens to guide the analysis.

Results: Findings from this study reveal how reproduction of actions manifests from nontechnical factors, such as cultural value, organisational structure, power relationship, human capacity, know-how and change management. These factors help to gain a more constructive and better understanding of how IT projects improvisation is influenced or impacted by nontechnical factors in organisations.

Conclusion: The study is intended to benefit both practitioners and academics. Some of the benefits will be gained from fresh perspectives on the complexities of IT projects improvisation, which are often caused by various seen and unforeseen non-technical factors. This includes how actions from relationship, know-how about facilities and communicative scheme are produced and reproduced.

\section{Introduction}

In the last two decades, the reliance on information technology (IT) by organisations has increased tremendously. Many organisations can hardly function or carry out their processes and activities without IT (Olugbode, Richards \& Biss 2007). Organisations consider the capacity of the IT purposely for business objectives, which include services to their clients (Peak, Guynes \& Kroon 2005). IT activities in organisations are normally carried out through projects. However, the nature of IT itself does and clearly creates challenges for the organisations that deploy and use it in their pursuit for competitive advantage (Drnevich \& Croson 2013). The challenges are irrespective of the sector or organisation. According to Kellermann and Jones (2013), the disappointing performance of IT within the healthcare environment can be largely attributed to several factors, which affects its improvisation. Thus, Creswell and Sheikh (2013) relate to complex web of interrelated social and technical issues situated within an environment.

Improvisation of IT projects for organisations' competitiveness depends partly on actors' roles, responsibilities and competencies. According to Heeks (2006), actors play a key role in the improvisation of both design and reality, so as to help improve success rates. This could be attributed to the fact that improvisation is embedded into the intricate of activities of IT projects, which affects its success or failure (Ciborra 1996). Also, participating actors, such as IT managers and IT project managers must therefore be able to first competently make effective use of the technology that they are to manage its deployment and use (Schwalbe 2015). This requires knowledge that is based on convention, which is described in structuration theory by Giddens (1984), as a junction where two or more people possess, is a shared knowledge. The shared knowledge allows them to make sense or understand and interpret what is being communicated. The communication forms part of project to deliver IT solution. In Chae, Koh and Prybutok's (2014) argument, organisations with IT capability demonstrates better business performance than their counterparts. 
Individuals' acceptance and use of IT has matured over the years (Venkatesh, Thong \& Xu 2012). The usefulness and intention to use could also be influenced by their individual or group knowledge, common sense and sense-making of the technologies. Giddens (1984), through his structuration formation, argues that common sense is more than acts of habit, which is attributed to how employees fall in the habit of doing certain things in the organisation. The habits adopted, eventually become the norm, an accepted way of doing things, which is not necessarily the better way. Thus improvisation of IT projects involves both technical and nontechnical factors (Rankin, Dahlbäck \& Lundberg 2013), which manifest from human actions, based on their understanding and interpretations of its significance to them.

The study examines the factors which influences and impact IT projects, improvisation, and how improvisation manifests. Thus, the research question is, what are the nontechnical factors that influence IT projects improvisation in organisations? The remainder of this article is structured into five main sections. The first section presents review of literature, which is split into two parts, to cover IT project and structuration theory. The approach that was employed in the study is discussed in the second section. The analysis, using structuration is presented in the third section. The findings and discussion are covered in the fourth section. Finally, a conclusion is drawn.

\section{Literature review}

Review of literature was conducted in the areas of IT project and structuration theory as they relate to improvisation:

\section{Information technology project}

One cannot deny the importance of IT projects in an organisation (Thomas \& Fernández 2008), which are often undertaken by individuals or group on behalf of an organisation to deliver specific goal and objectives, overtime, using available resources (Bardhan, Krishnan \& Lin 2013). As shown in Figure 1, IT project involves technology and nontechnological capacity, which are further divided into units and sections of activities, depending on the nature and

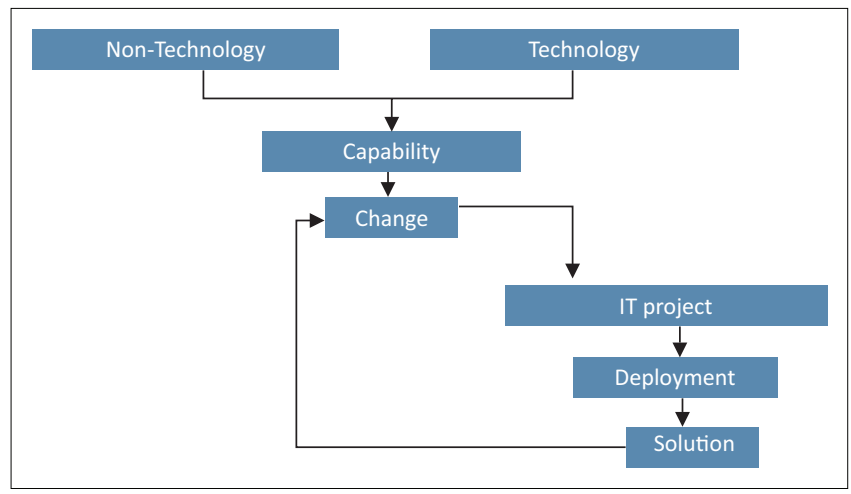

Source: Letseka, M. \& Iyamu, T., 2011, 'The dualism of the information technology project, in The Proceedings of the 2011 Annual Conference of the South African Institute of Computer Scientists and Information Technologists, Cape Town, October 3-5, pp. 294-297

FIGURE 1: Information technology project factors. requirements for the project. The activities influence IT project improvisation through deliberate action of employees in their quest to deliver plan, on behalf of the organisation (Bansler \& Havn 2004). As illustrated in Figure 1, the factors that are essentially required to engineer technology to desirability are of non-technology nature. For example, the process that is involved in the configuration of a technology in the context of an organisation is as important as the technology itself. This could be an opposing justification to actor-network theory of asymmetry formulation that human and non-human actors are equal within a network. According to Iyamu (2015:90), the fact is that non-human actors, such as technologies are created by humans, in essence, humans are competing with themselves for power through their own innovations, which inevitably cannot do without at times.

Technology is an object, external force which impact system within a social structure in IT projects improvisation (Rankin, Dahlbäck \& Lundberg 2013). The relationship between technology and humans has been seen as a product of shared interpretations or interventions for many years (Orlikowski 1992). Improvisation of IT projects is primarily intended for organisational benefits and competitiveness. According to Carver and Turoff (2007), improvisation can be used to appraise how decision are made or formulated in carrying IT activities. Thus, Vaidya, Sajeev and Callendar (2006) propose a framework that could checkmate actors' activities towards assisting in projects, to minimise failure. In Sauer and Reich's (2009) assessment, there are five key 'directions' that could be employed in the implementation of projects, which include complexity, social process, value creation, broader conceptualisation of project and reflective practice.

Understanding of the word 'failure' in the context of IT projects could be associated with subjectivism. Thus, we clarify in perspective that under-utilisation or abandonment of an IT project represents failure (Yeo 2002). Failure has been synonymous with IT projects for many years, and across industries (Al-Ahmad et al. 2009). It could be caused by any or combination of factors, including people's efforts on the use of technology, which weakens or limits the strength of the relationship between behavioural intention and actual use of the technology use (Venkatesh, Thong \& Xu 2012). However, Stoica and Brouse (2013) argue that many of the research that has been conducted on IT projects to date focus on 'success' factors, and less work focus on 'failures' and their respective potential root causes. Perhaps the subject of project failure is inevitably too soiled with managerialist, positivist or performative intent, which is based on thoughts and actions (Sage, Dainty \& Brookes 2014). Improvisation occurs in an environment where there are various thinking and action of people happen simultaneously towards deliverable of (Ciborra 1996). Lind and Culler (2013) suggest that because IT projects involve many stakeholders, it take longer time to accomplish.

The stakeholders extend beyond the IT unit, to business personnel, users and executive managers, and they exercise 
different roles and responsibilities, which are influenced by their power to make a difference. Power is multidimensional, and it is directly or indirectly imbibed into human activity in accordance to individual interests and values (Castells 2011), which could have manifest in the process of improvisation. This could be attributed to the fact that power is a socially shaped construct, which focuses on building influence within network, and instrumental in decision making and planning (Beritelli \& Laesser 2011). Also, actions from power could be attributed to manifestation of politics, which impact on how an organisation functions, the processes in the organisation and how decisions are made (Iyamu \& Roode 2010), which is influenced by factors, such as processes, norms, culture and resources in their context and relevance. Improvisation appears to be a highly interactive process with social dimensions, which embeds human behaviour (Ciborra 1996). Thus, we employ structuration theory in order to gain better understanding of the factors that influence IT project improvisation in an organisation.

\section{Structuration theory}

Structuration is a sociotechnical theory which focuses on agent, structure and interaction. Interaction within a social system relies on how human actions are enabled or disabled through the organisational structures, which are interestingly a result of previous actions (Orlikowski \& Robey 1991). Structuration, implicitly states that the agents' actions are conditioned by the organisational properties in social contexts (Iyamu \& Roode 2010). The theory examines different assumptions include knowledge and techniques, which manifest from different practices and actions.

Structuration is a process of reproducing the duality of structure over time and space (Gao \& Lyytinen 2003). As in Figure 2, the duality of structure contains three dimensions, which include structure, modality and interaction, in which both structure and interaction are linked through modalities: the interpretative schemes, resources and norms.

Structure comprises of three fundamental elements, signification, domination and legitimation. The structures are linked to agents through their interaction, which happens in dualism. Institutions are made up of the actions of agents in a social system, such as project team and an organisation. Agent actions are materialism of the structures. The modalities (interpretative schemes, facility and norms) link the process of interaction (communication, power and

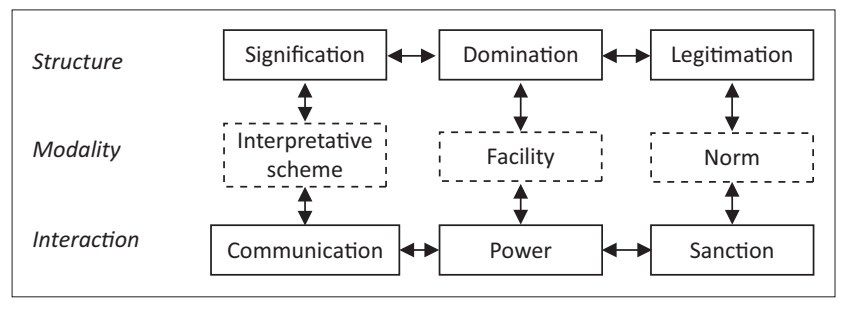

Source: Giddens, A., 1984, The constitution of society: Outline of the theory of structure Berkley, CA, University of California Press

FIGURE 2: Duality of structure. sanction) with the structural components (signification, domination and legitimation) of social, systems (Giddens 1984). The modalities are also the interaction between the agents and the structures in the features of a social system which are closely connected and yet the agents are capable of acting freely in the system (Giddens 1984). Bottom-line is that structuration is 'an effort to reconstruct the basic premises of social analysis' (Giddens 1991:205). The theory can therefore be used as a means to examine the interplay between the agent and structure (Buhr 2002).

\section{Research approach}

The case study approach was applied in the study. Studying real-life situation, which the case study flexibly allows was the main justification for selecting the approach (Yin 2013). The other rationale was that the approach allows selection of vast pool of individuals and groups within a case (Ritchie et al. 2013). The IT department of a South Africa-based telecommunication organisation was used in the study. The company is listed in the Johannesburg Stock Exchange (JSE) since the year 2000. It had about 200 personnel in its IT department.

A total of 31 people at both senior and junior levels from IT (x21) and business (x10) units were interviewed at the point of saturation. The participants were labeled as follows: between TELIT01 and TELIT21 for IT; and between TELBU22 and TELBU31 for business.

Three main questions were used in the qualitative data collection: (1) How are IT projects improvised in the organisation? (2) What are the factors that influence improvisation of IT projects in the organisation? and (3) How are IT projects tasks assigned and carried out? The transcripts of the interviews were confirmed by the interviewees. The interpretive approach was employed to subjectively analyse the qualitative data that were gathered, with particular focus on the non-technical factors which manifest in the improvisation of IT projects in organisations. The interpretive approach is socially constructed in a natural setting of reality, and does not predefine variables, but aims to produce an understanding of the social context of the phenomenon (Rowlands 2005). In the use of interpretive approach, the duality of structure (see Figure 1) of the structuration theory was followed, as lens, to examine non-technical factors' reproductive actions, in order to gain better understanding of the factors that influences improvisation of IT projects in organisations.

As discussed in the 'Information technology project' section, the duality of structure from the perspective of structuration was employed in the analysis of the data for two main reasons: (1) the theory focuses on social process that involves the interaction amongst agents, using available structures, which can include technology designers, users and other decision makers in a project, and (2) it examines how events and interactions are reproduced over time within a social system, such as organisation and project team. 


\section{Information technology project viewed through the lens of duality of structure}

Improvisation of IT project was viewed, using the duality of structure from structuration theory. Thus, structure, modality and interaction were followed in the analysis. This was to examine and understand non-technical factors manifest in the improvisation of IT projects, which influences success or failure in many organisations.

\section{Duality of structure}

As defined by Giddens (1984), duality of structure consists of three main components - structure: signification, domination and legitimation; modalities: interpretative schemes, facility and norms; and interaction: communication, power and sanction.

\section{Signification and/or interpretative scheme and/or communication}

The outcome, success or failure of improvisation of IT project is influenced by its significance to the organisation and the agents (stakeholders) that undertake the various sponsorship, technical and management tasks in a project. Signification illustrates the differentiation of values that is associated to object or subject within an entity, such as improvisation of IT project. Thus, the significance of an IT project is not always obvious as it is not necessarily its size or cost. The significance of IT projects is therefore influenced by how agents interpret the requirements including rules and regulations in the tasks that are assigned to them. According of one of the business analysts who participated in the study:

'some IT managers determine the importance of IT project improvisation based on the types of skill-set that are deployed in it. This is because our organisation sometimes deployment people into IT projects for the sake of keeping them busy.' [TELBU23]

The interpretation and subsequent understanding of requirements, rules and regulations is based on knowledge. Another critical factor that influences interpretations is individual's interest or organisation's or both interests. The interpretation that happens during improvisation of IT projects is primarily shaped by how the tasks and associated factors were communicated to the interpreters (stakeholders). What makes the interests more challenging towards the outcome of a project is that many managers take for granted how their subordinates understand their communication to them. Giddens (1984) attributes this type of behaviour to the unconscious categories of the mind that makes up the sentiments of the selfhood. Employees therefore act knowing fully that it impact the outcome of their IT project improvisation. This is attributed to the fact that some of them do not think that their expertise and opinion are taken seriously. This could be ascribed to some managers' over reliance on formal communication, which was well structured in the organisation as at the time of this study. One of the employees explains as follows:
'The Company has created website for communication and information purposes regarding projects. Our communications also happen through emails. There are collaboration tools, such as NetMeeting and Communicator, which we use as well in our IT projects. Yet, we have difficulty in understanding ourselves and gathering some relevance information about projects, such as interpretation of software development standards, and business and IT requirements' alignment.' [TELIT19]

This is primarily because many managers continue to pay attention to what they solely think it significance to the project, and not why things happen in the way that they did, such as how communication is carried out and received, how the interpretation of those communications. This affects team's cohesiveness and collectiveness, from the perspectives of allocation and execution of tasks. One of the business analysts who participated in the study shares her view as follows:

'The business architecture department is tasked with ensuring the requirements and scope provided to the project team is detailed enough to provide the business with their needs, of which we cannot be involved in the execution.' [TELBU25]

Managers and some employees seem, and continue to put emphasis on technology and other outcomes, and not the factors that manifest themselves into those outcomes. This could be attributed to some of the reasons why improvisation of IT projects continue to be challenged, after years of invented and application of sophisticated and improved processes. According to a software developer, he (the project manager):

'doesn't see the end-to-end picture. He doesn't care about the end-to-end picture. He only cares about the task that he must manage in the projects, which are basically to meet deadlines, save cost and fulfil requirements.' [TELIT09]

An agent can make sense of his or her own actions as well as other people's actions in the same social system, within the frame of their interest or knowledge, or both. The relationship between an agent and the system is therefore a methodological experience, which manifest from structure of signification overtime and space. Structures and communications are affected by individual or group of individuals' interpretative schemes within a social system, which manifest reproductively to give a certain favourable or unacceptable outcome. Agents interpret and internalise information that is communicated to them, and from this they act, which produces the end results. The agents may not justify the actions they take for various reasons, such as job security and know-how. Their actions are sometimes determined and influenced by the rules of a project or in the organisation. This could be ascribed to enact their source of power, to deterministically influence the facilities that are employed or not used in the improvisation of IT projects within the organisation.

\section{Domination and/or facility and/or power}

Improvisation of IT project happens within constitute of agents, which includes facilities, such as finance, rules, regulations and human capacity. The agents are used either 
as means or end towards achieving the objectives of the project. Therefore, a resource (facility) or combination of resources dominates or can be used to dominate in the process. This explains why in improvisation of IT project an activity can be held significantly high, and irrespective of the cost, to achieving the objectives of the project. This also reveals why individuals are able to use the facility within their means to influence activities in order to get favourable results, which are not necessarily for the interest of the organisation. According to one of the technical personnel in the organisation:

'Sometimes we were not privileged to how tasks were allocated. We often have little or no choice but to accept. Otherwise, we could be charged for insubordination. However, we make use of what means which is on our disposal to respond to the allocated task, such as requirements gathering and analysis, project design and technical documentation.' [TELIT13]

This was an interesting piece of revelation. However, the respondent was not comfortable in expanding further.

A facility become dominant factor, or is used to dominate based on agents' interpretation, which they envisaged it could make different in the activities or overall outcome of IT project improvisation. The dominant factor is therefore used as a source of individuals' power, to make a difference in a project within an environment. Sauer and Reich (2009) identify and emphasise the importance of being able to control the project team using the mandated power that is bestowed on the focal actor, as prescribed by the rules and regulations of the organisation. Power is a phenomenon, which involve control of resources for a specific task at different stages. The source of power varies, and it is not explicit or restricted to certain individuals or groups. They are identified as knowledgeable agents of domination, which is not permanent across projects. Employees' actions during a project have to demonstrate a certain kind of power to be able to make a difference, which determines the success or failure at the end. In the expression of a participant:

'We all have different types of skill, some are of technology know-how, and others are of social nature, such as how to get colleagues to do the right or wrong thing, which include adherence to standards, requirements and documentation in the process of project execution.' [TELIT15]

Thus, mangers of IT project do not take cognisance of, or do not know to do so. They begin and continue to look at results and not how they achieved the results or found themselves the position. An employee expressed his views as follows:

'Two things were primarily wrong with the allocation of tasks in the improvisation of many IT projects in our organisation: (1) imbalance of workload and (2) inappropriate alignment of individual skills with the tasks that are assigned to them, such as business analysts, software development and IT architects.' [TELIT08]

These are fundamental factors that develop into power that various actors tap upon, in attempt to assert themselves.
Power can be exercised by any individual or group in the improvisation of IT project in organisations. Every team member that is deployed to an IT has a certain level of power, by virtue of their knowledge of the project or the task that is assigned to them. Therefore, they have the ability to influence the outcome of the project, directly or indirectly. The source of power is extended to know-how of facility to a make a difference within the context of the task that was assigned to them in a project. Ignorantly, some IT project managers continue to undermine certain individuals by taking their power for granted, or lack the know-how to establish the extent of the influence of individuals' power to make a difference. This type of acts can be associated to Giddens (1984) description of practical unconsciousness, a certain type of action informed by knowledge that is implicitly carried out, but rarely expressed or articulated. Employees exhibit certain practical consciousness or stock of knowledge in an organisation, which with time are accepted and consequently considered norm, as they interpret their interactions during IT project improvisation. This stock of knowledge develops from a facility to source of dominant, and they are imprinted on others legitimately.

\section{Legitimation and/or norm and/or sanction}

An IT project takes effect after being approved by the relevant authority within an organisation. The approval legitimises the project, based on its adherence to the prescribed processes, which are considered to be norm in the organisation. This process or processes might not be perfect, but they are acceptable by majority of the agents who are involved or do have impact upon. As echoed by both software developers and IT project managers in the organisation:

'We do not follow process of best practices but our software that are developed in-house can be measured against the best'. [TELIT03 ]

Legitimisation of an IT project is done through structure, towards achieving its goal primarily for competitiveness. In duality, the structure of legitimation is created by agents, for the same agents, in the execution of their activities in IT projects. The structure of legitimation of IT project is carried out by agents through processes, using available facilities that are considered to be norm, which is not necessarily the correct approaches, but because they were sanctioned by those that are involved in the activity. This has serious impact on the project, which are often negative and challenging:

'It is better to embark on the right process, of innovative and creativity rather than this is how we have been doing it, according some of the employees who was relatively new, about three years in the organisation.' [TELIT02]

In the improvisation of IT projects, there are facilities that can or cannot be employed, do's and do not's, purposefully for the benefit of the project and the organisation at large. These are also to abide by the beliefs and culture of the organisation, including the requirements of the project. The dos and don'ts, which were created by an individual or 
group of them, become the norm overtime through which improvisation of IT projects were carried out in the organisation.

Employees endorse their actions by drawing on norms or standards of morality as they deemed acceptable within a project. The major implication of this is that in improvisation of many IT projects, the designers are not necessarily the implementers. Thus, there are sometimes conflicting views, which draws on the application of what is considered to be norm at the time, for resolution purposes. This could be attributed to why many IT projects are difficult to implement, as the users and implementers did not together sanction some of facilities and activities.

Employees' attitudes and behaviours can be linked to organisational structure and culture. Attitude inadvertently determines how individuals in an organisation respond to inhouse and external changes, which does have a bearing on the outcome of IT project improvisation. The people in an organisation are most likely to behave in a similar manner when faced with a challenge. This is because they are together exposed to the same environment. This does not however suggest that people will always behave in the same manner; it merely suggests that they are inclined to reacting similarly unless one taps into their individual capabilities to make a difference.

\section{Findings and discussion}

The analysis as presented above through the duality of structure as a lens from the perspective of structuration theory reveals the non-technical factors, which influence and impact improvisation of IT projects in organisations. As shown in Figure 3, the factors include cultural value, organisational structure, power relationship, human capacity, know-how and change management. These factors are produced and reproduced over time through a duality in the improvisation of IT projects. The factors as depicted in Figure 3 should be read with the discussion that follows in order to gain a more constructive and better understanding of how improvisation of IT projects is influenced or impacted by non-technical factors.

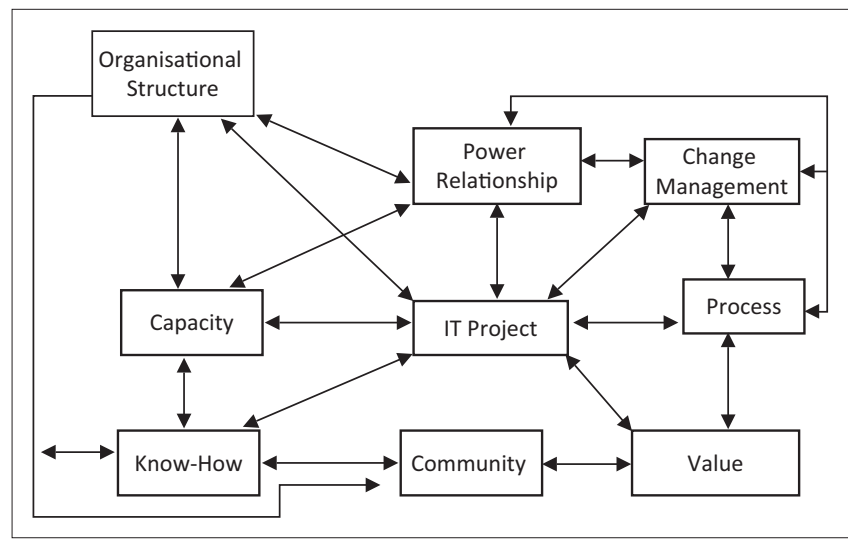

FIGURE 3: Dualism of information technology project improvisation.

\section{Cultural value}

Cultural value of an organisation is formulated overtime, primarily to uniformly guide their employees towards ensuring sustainability and competitiveness. It therefore drives the focus of the organisation, and influences the outcomes of its activities. Thus, IT project improvisation considers or aligns with the cultural value of the organisation. However, there are some fundamental that can be associated to the outcome of IT projects in an organisation. The challenges result from the following questions: (1) At what stage of the project is the cultural value considered? (2) How is the cultural value considered or aligned with the objectives of the project? and (3) Which of the entities takes priority, the IT project improvisation or cultural value?

The values of an organisation are enforced through a dualistic process in accordance to the structure (rules and resources), over dialogue as informed by interpretation within a communicative scheme. Organisational values are enforced because of their significance, mainly to dominate individuals' personal belief or interest, through a legitimate process.

\section{Organisational structure}

Organisational structure is different from structure in structuration theory, as defined by Giddens (1984) and clarified by Iyamu and Roode (2010), in that structure is rules and resource. Organisational structure is created or followed during IT project improvisation. This is to guide roles and responsibilities, which defines allocation of tasks. Also critically important in improvisation of IT projects are rules and resources, which are created by the employees, within which the creators themselves operate. The organisational structures help to define factors, such as rules, regulations, responsibilities, reporting lines, technology resource and the communication format amongst the stakeholders, which influence, not in a deterministic sense, the outcome of IT project improvisation, directly or through manifestation.

People and process constitute the entity known as the organisation, which consists of power, upon which relationships are built, and defines how communications are carried out amongst employees within an IT project. As communications of the same subject take place, but at different levels of the organisation, interpretation is enshrouded with various contexts, which has impact on IT project improvisation. The question is: how many IT projects managers consider this as a critical factor?

Many organisations follow hierarchical structures with defined reporting channels. This is referred to as a formal organisational structure. The hierarchical structure is argued to follow a rigid communication structure, where information is filtered from the top to bottom levels. One of the challenges is that the communication channel is not dualistically structured, to flow from bottom as it does from top to bottom. 
An organisational structure dictates how the employees communicate and carry out their activities. Also, the organisational formal structure dictates the reporting lines as employees interact in the formal environment of the organisation. As a result of the lack of dualism in the communication channel that is caused by organisational structure, individuals begin to react through their personal interpretation of technology artefacts, as well as the processes that are involved in IT project improvisation. Through the interpretation, they begin to build their power as a form of self-defence or self-reliance.

\section{Power relationship}

As revealed in the analysis, employees do not only produce and reproduce rules and resources, they also have the ability to control and influence improvisation of IT projects in their organisations. This is often for their personal or organisation's or both interests, which of course influences the outcome of projects. In the course of producing and reproducing of activities, relationship is experienced. Thus, individuals and groups tap on available power to define a favourable relationship, which ultimately have impact on improvisation of IT projects. This has been difficult to identify by many IT project managers as they are not psychologists, who can possible read and understand the traces of the minds of the employees.

What makes the relationships that are founded on power to manage is that they are drawn and shaped legitimately through the rules and regulations, using the available resources of the organisation. Thus, power relationship enables and at the same time, constrain IT projects improvisation in organisations. IT project managers find it difficult to manage constrains that are caused by practical unconsciousness, in that the actions cannot be explained by the employees who carries out such acts. What makes it even more challenging for some IT project managers is the fact that human capacity is inseparable from their conscious and unconscious behaviours.

\section{Human capacity}

Human capacity is critically vital in some organisations, as it is considered to be the most valued resource in realisation of IT projects. People are the foundation of an organisation in that there is no organisation without people. People therefore make up the norms, values and culture of an organisation, through which they create capacity to make difference in the improvisation of IT projects, whether consciously or subconsciously.

The individual influences in an organisation have the potential to contribute to IT project improvisation through shared beliefs, practices and values. Values and practices within an IT project are found in the symbols, which reproduces the outcome. The challenges and gaps that exist in project managers' lack of ability to identify the values and practices from project team members' perspectives.
Employees in an organisation have their own perceptions, which allow them to accept or reject how activities of IT projects improvisation are problematised for them. This action of acceptance or rejection does not happen voluntarily. It is in fact driven by the leaders in the projects, in a reproductive manner. For example, the chief executive officer explores his or her ability and power to influence how improvisation of IT projects are shaped. The action could be as a result of know-how or lack of know-how.

\section{Know-how}

Agents have the ability to express reasons for why they do what they do in the improvisation of IT projects. They may however, not be able to explain the source of what drives their actions, but there are consequences and implications. Some of the things an employee does are intertwined in his or her mind as knowledge gained through practical consciousness. An agent does certain things without particularly being aware of their actions, which negatively or positively impact the project. The action of the agent takes place within rules and available resources, in that it legitimatises as part of the organisational norm. Based on their knowledge, actions are produced and reproduced with the duration of the IT project improvisation.

The unequivocal actions of employees, which affects IT projects improvisation, can be divided into two types of knowledge. In structuration, there are two types of knowledge: discursive knowledge and practical knowledge. Discursive knowledge is the knowledge which agents in an organisation are able to articulate, whilst practical knowledge refers to the tacit knowledge that agents draw from. When working in a project, there are activities or tasks an agent does, which he or she cannot explain. In some cases it might be things that they do because they knows just how to do them or the things an individual has been doing for so long, they have become a part of them. This is reproduction of results relatively to agents' reproductive actions. This therefore requires change management, which many IT project managers consider a different role and responsibility to theirs.

\section{Change management}

Change management seems inevitable in some organisations, in the improvisation of IT projects. Change management is a legitimate facility that is often used to support and enable processes and activities. Without change management, it is difficult to embark on during transition of events in IT projects improvisation. However, change management can also be a constraining factor to the events that it was supposed to support and enable. This could be attributed to interaction and interpretation of the communication about project tasks and activities. It therefore involves a process of negotiation between the focal actors and other stakeholders; hence the process has to be of dualism.

The change management process is not the function of the project manager alone, we do concede. Another important 
reveal in this study, and that must be taken cognisance of, is that change management happens at different, small- and large-scale levels. This is in lieu of the fact that the change manager is expected to ensure smooth transition of a technology into an environment, which this study empirically reveals is the responsibility of the IT project managers. Adopting a new system in an organisation is not an easy task; transition from current to desired state could be challenging. In an organisation, where changes are communicated and implemented as directives and instruction without exchange of information in the form of dualism, it becomes complicated in ensuring that enough is known for the decisions that were taken.

\section{Process}

Process is an ongoing activity in an organisation that entails engagement and interaction between employees in a specific purpose. Improvisation of IT project is unique irrespective of the technology and the organisation. It is carried out differently in organisations, by various people at a time. Also, it is simultaneously managed and constantly revisited with every new project in order to fulfill relevance, and to align with context. The process is a process in itself, in that through a process a process is formulated, resulting from dualism.

Improvisation of IT projects is process oriented. The rationale for implementing certain projects remains a challenge to those that are involved because of the nature of some processes. Each part that is involved in IT projects improvisation has a role to play, whether in the development or management process. In some instances, the role is determined by the individual's interest or the deterministic nature of the involving process. Hence communication amongst the stakeholders is critically important.

\section{Conclusion}

Improvisation of IT projects has been a cumbersome process or exercise in organisations for many years. The use of structuration theory as a lens in the empirical study helps in this regard, to examine, and reveals complexities of nontechnical factors. The findings from the study provide a guide and facilitates improvisation of IT projects in an organisation. Thus, the study benefits both business and academia.

Managers will gain better understanding from how human actions are reproduced, to enable and at the same time constrain processes and activities in the improvisation of IT projects in their organisations. Academics will equally benefit from this study, particularly how structuration theory was employed to examine and understand the nontechnical factors, which influence improvisation of IT in organisations. Also, the study contributes to existing literature in the areas of IT project and management. However, future studies can be undertaken to explore, examine and understand how human and non-human networks are formed, and how their roles can be used to assess the deployment of IT projects.

\section{Acknowledgements Competing interests}

The author declares that he has no financial or personal relationship(s) that may have inappropriately influenced him in writing this article.

\section{References}

Al-Ahmad, W., Al-Fagih, K., Khanfar, K., Alsamara, K., Abuleil, S. \& Abu-Salem, H., 2009 'A taxonomy of an IT project failure: Root causes', International Management Review 5(1), 93.

Bansler, J.P. \& Havn, E.C, 2004, 'Improvisation in information systems development', in B. Kaplan, D.P. Truex, D. Wastell, A.T. Wood-Harper \& J.I. DeGross (eds.), Information systems research, pp. 631-646, Springer, Boston, MA.

Bardhan, I., Krishnan, V. \& Lin, S., 2013, 'Team dispersion, information technology, and project performance', Production and Operations Management 22(6), 1478-1493. https://doi.org/10.1111/j.1937-5956.2012.01366.x

Beritelli, P. \& Laesser, C., 2011, 'Power dimensions and influence reputation in tourist destinations: Empirical evidence from a network of actors and stakeholders', Tourism Management 32(6), 1299-1309. https://doi.org/10.1016/j. tourman.2010.12.010

Buhr, N., 2002, 'A structuration view on the initiation of environmental reports', Critical Perspectives on Accounting 13(1), 17-38. https://doi.org/10.1016/S10452354(00)90441-6

Carver, L. \& Turoff, M., 2007, 'Human-computer interaction: The human and computer as a team in emergency management information systems', Communications of the ACM 50(3), 33-38. https://doi.org/10.1145/1226736.1226761

Castells, M., 2011, 'Network theory|A network theory of power', International Journal of Communication 5, 15.

Chae, C., Koh, E. \& Prybutok, R., 2014, 'Information technology capability and firm performance: Contradictory findings and their possible causes', MIS Quarterly 38(1), 305-326.

Ciborra, C., 1996, 'Improvisation and information technology in organizations', in The Proceedings of International Conference on Information Systems, Association for Information Systems, Cleveland, OH, USA, December 16-18, 1996, pp. 369-380.

Creswell, K. \& Sheikh, A., 2013, 'Organisational issues in the implementation and adoption of health information technology innovations: An interpretative review',
International Journal of Medical Informatics 82(5), e73-e86. https://doi. org/10.1016/j.ijmedinf.2012.10.007

Drnevich, P.L. \& Croson, D.C., 2013, 'Information technology and business-level strategy: Toward an integrated theoretical perspective', MIS Quarterly 37(2), 483-509.

Gao, P. \& Lyytinen, J., 2003, 'China telecommunications transformation in globalization context: A structuration perspective', In Proceedings of IFIP/TC8.2 and 9.4 Working Conference on IS Perspectives and Challenges in the Context of Globalization, pp. 217-233, Athens, Greece, June 15-17.

Giddens, A., 1984, The constitution of society: Outline of the theory of structure, Berkley, CA, University of California Press.

Giddens, A., 1991, 'Structuration theory: Past, present and future,' in C. Bryant \& D. Jary (eds.), Giddens' theory of structuration: A critical appreciation, pp. 201-221 Routledge, London, UK.

Heeks, R., 2006, 'Health information systems: Failure, success and improvisation', International Journal of Medical Informatics 75(2), 125-137. https://doi. org/10.1016/j.ijmedinf.2005.07.024

Iyamu, T. \& Roode, D., 2010, 'The use of structuration theory and actor network theory for analysis: Case study of a financial institution in South Africa', International Journal of Actor-Network Theory and Technological Innovation 2(1), 1-9. https://doi.org/10.4018/jantti.2010071601

Iyamu, T., 2015, Application of underpinning theories in information systems, Heidelberg Press, Australia.

Kellermann, A.L. \& Jones, S.S., 2013, 'What it will take to achieve the as-yet-unfulfilled promises of health information technology', Health Affairs 32(1), 63-68. https:// doi.org/10.1377/hlthaff.2012.0693

Letseka, M. \& Iyamu, T., 2011, 'The dualism of the information technology project,' in The Proceedings of the 2011 Annual Conference of the South African Institute of Computer Scientists and Information Technologists, Cape Town, October 3-5, pp. 294-297.

Lind, M.R. \& Culler, E., 2013, 'Information technology project performance: The impact of critical success factors', Perspectives and Techniques for Improving Information Technology Project Management 39.

Olugbode, M., Richards, R. \& Biss, T., 2007, 'The role of information technology in achieving the organisation's strategic development goals: A case study', Information Systems 32(5), 641-648. https://doi.org/10.1016/j.is.2006.04.001

Orlikowski, W.J., 1992, 'The duality of technology: rethinking the concept of technology in organisations', Management of Technology 3(3), 398-427. https:// doi.org/10.1287/orsc.3.3.398

Orlikowski, W.J. \& Robey, D., 1991, 'Information technology and the structuring of organisations', Information Systems Research 2(2), 143-169. https://doi. org/10.1287/isre.2.2.143 
Peak, D., Guynes, C.S. \& Kroon, V., 2005, 'Information technology alignment planning-A case study', Information \& Management 42(5), 635-649. https://doi. planning-A case study', Inform
org/10.1016/j.im.2004.02.009

Rankin, A., Dahlbäck, N. \& Lundberg, J., 2013, 'A case study of factor influencing role improvisation in crisis response teams', Cognition, Technology \& Work 15(1), 79-93. https://doi.org/10.1007/s10111-011-0186-3

Ritchie, J., Lewis, J., Nicholls, C.M. \& Ormston, R. (eds.)., 2013, Qualitative research practice: A guide for social science students and researchers, Sage, Washington, DC

Rowlands, B., 2005, 'Grounded in practice: Using interpretive research to build theory', The Electronic Journal of Business Research Methodology 3(1) 81-92.

Sage, D., Dainty, A. \& Brookes, N., 2014, 'A critical argument in favor of theoretical pluralism: Project failure and the many and varied limitations of project https://doi.org/10.1016/j.ijproman.2013.08.005

Sauer, C. \& Reich, H., 2009, 'Rethinking IT project management: Evidence of a new mindset and its implications', International Journal of Project Management 27(2), 182-193. https://doi.org/10.1016/j.ijproman.2008.08.003
Schwalbe, K., 2015, Information technology project management, Cengage Learning, Boston, MA.

Stoica, R. \& Brouse, P., 2013, 'IT project failure: A proposed four-phased adaptive multi-method approach', Procedia Computer Science 16, 728-736. https://doi. org/10.1016/j.procs.2013.01.076

Thomas, G. \& Fernández, W., 2008, 'Success in IT projects: A matter of definition', International Journal of Project Management 26(7), 733-742. https://doi. org/10.1016/j.ijproman.2008.06.003

Vaidya, K., Sajeev, A.S.M. \& Callender, G., 2006, 'Critical factors that influence e-procurement implementation success in the public sector', Journal of Public Procurement 6(1/2), 70.

Venkatesh, V., Thong, J.Y. \& Xu, X., 2012, 'Consumer acceptance and use of information technology: Extending the unified theory of acceptance and use of technology' MIS Quarterly 36(1), 157-178.

Yeo, K.T., 2002, 'Critical failure factors in information system projects', Internationa Journal of Project Management 20(3), 241-246. https://doi.org/10.1016/S02637863(01)00075-8

Yin, R.K., 2013, Case study research: Design and methods, Sage, California, CA. 